\title{
Application of Confucian Cultural Concepts in the Landscape Design of Chinese Architecture
}

\author{
Lin Zhang ${ }^{1, a}$, Zhi You,b \\ ${ }^{1}$ Chengdu Art Vocational Collage, Chengdu City, Sichuan Province, 611433, China \\ ${ }^{2}$ Sichuan Technology and Business University, Chengdu City, Sichuan Province, 611745, China
}

Keywords: Confucian culture; Architecture; Landscape design; Application

Abstract. Confucian culture is the mainstream of Chinese traditional culture, which has played an indelible role in Chinese history, and had a wide and profound influence on modern society. At present, most of the cultural phenomena in China's social and economic life are based on the Confucian cultural ideas, and the typical one is the architectural landscape design. In this paper, based on the author's research results, we analyzed the application of the concepts of great virtue, rites and music, solidarity and harmony in Chinese architectural landscape design.

\section{Introduction}

Confucian culture is the mainstream of Chinese traditional culture, which has played an indelible role in Chinese history, and had a wide and profound influence on modern society. At present, most of the cultural phenomena in China's social and economic life are based on the Confucian cultural ideas, and the typical one is the architectural landscape design. With the rapid development of China's social economy, China's economic development mode begins to transform to the resource-saving and environment-friendly direction, and architectural landscape design also begins to pursue the environmental integration and natural harmony, which coincides well with Confucianism. It is foreseeable that Confucian culture will be an important guiding ideology of China's architectural landscape design in future.

\section{The Embodiment of Confucian Culture in Architectural Landscape Design}

Confucian culture has a very rich connotation, and plays a core and main role in the course of the development of Chinese ancient culture, whose basic spirits can be summarized as the vigorous spirit of self-improvement, the patriotic spirit of integrity-advocating, the world's salvation spirit of practical statecraft, the people-oriented spirit that the people are more important than the ruler, the humane spirit of great virtue and the like. The cultural connotation of Confucian culture covers almost all the cultural connotation of architectural landscape design in China, and guides the architectural landscape design activities. At the same time, Confucian culture is also carried forward deeply rooted in the long history of China's development by way of the architectural landscape design. It can be said that Confucian culture and Chinese architectural landscape design complement each other, and are indispensable. At the present time, architectural landscape design has developed into an all-encompassing comprehensive discipline, the penetration breadth of whose internal knowledge can be summarized as the mutual blending of art, architectural landscape, humanities, history, psychology, geography, and science and technology.

In the new development situation of architectural landscape design, the combination of Confucian culture with the architectural landscape design must also get rid of the stale, and bring forth the fresh. Therefore, the main problem in the field of architectural landscape design is the transformation problem of modern architecture landscape design and traditional Confucian culture. This problem has been well solved in some typical architectural landscape design such as the design of the Shanghai World Expo Chinese Pavilion (Figure 1). The cultural connotation expressed by the building itself is simple, frank and intriguing. Superficially, the "brackets" architectural design concept in the traditional Chinese architecture is reflected. However, in fact, the Chinese Pavilion 
expresses the unique concept of harmony in Chinese culture, which is the concentrated expression of national culture and national spirit.

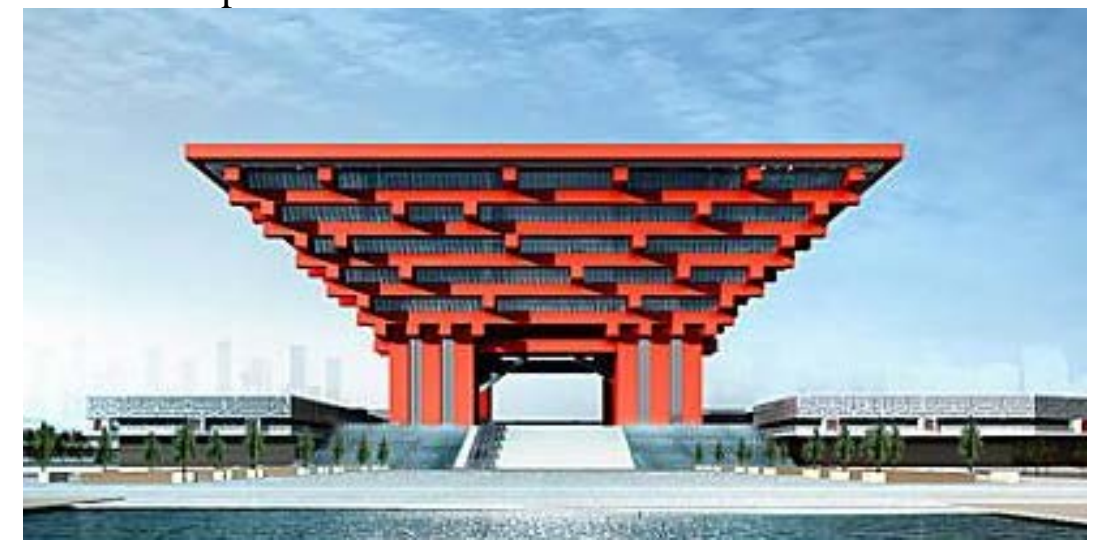

Fig.1 Design of Shanghai World Expo Chinese Pavilion

\section{The Guidance of Confucian Cultural Concepts to Chinese Architectural Landscape Design}

"Great virtue" in Confucian concepts is the core concept of Chinese architectural landscape design. Confucian spiritual and cultural ideas have a very rich connotation, which play a core and main role in the process of Chinese cultural development. Confucian spiritual and cultural ideas can be summarized as follows: the national spirit of self-improvement, the patriotic spirit of integrity-advocating, the world's salvation spirit of practical statecraft, the people-oriented spirit that the people are more important than the ruler, the humane spirit of great virtue and the like. It is these Confucian spiritual culture that plays an important guiding role in the formation of the architectural concept of Chinese architecture landscape design. Chinese architectural landscape design has wide subjects, rich connotation, and diverse forms, which is difficult to be replaced by other artistic forms. The great virtue in Confucian ideas is the essence of Chinese traditional culture, and an important part of Chinese architectural landscape design concept. The spiritual connotation of the great virtue can be summarized as the spirit of humanism. In the aspects of dealing with the relationship between human being and nature, Confucianism pays more attention to the role of people in the society, and advocates achieving the value of life through personal moral self-improvement, which attributes to form the characteristics of Confucian culture with the focus on humanities, morality and emotion.

Based on the practice of Chinese traditional architectural landscape design, the spiritual and cultural resources of great virtue in traditional Confucian concepts can be made full use of. According to the development and change of the times, the new connotation should be attached to Chinese architectural landscape design. The essence of Chinese architectural landscape design is the characters of virtue-advocating, virtue-emphasizing and great virtue. The spiritual culture of Confucianism great virtue has a strong vitality. Only if the cultural connotation of great virtue in Confucian concepts is embodied in the architectural landscape design, can it have real vitality. Only if the characteristics of the spiritual and cultural concepts of great virtue in Confucian concepts is reflected in the design ideas, can it truly give spiritual comfort and a sense of belonging to human being.

"Rites and music" in Confucian cultural concepts is the concept of Chinese architectural landscape layout design. National culture is the rites and music culture with the core of "moderation" spirit. The rites and music cultural ideas have also had an important influence on the Chinese classical artistic spirit, which are materialized as solemn, orderly, natural and free design aesthetic pursuit in the process of construction, landscape garden and art development. The rites and music culture is also the most valuable core spirit and concept in Chinese cultural schools. "Rites" refers to the communication between people's own subject consciousness, and "cultural existence" beyond their own consciousness, which has a function of social normative integration. The feature of rites is "orderly". Under the promotion of Confucianism, the rites are the intermediary agent for the 
communication between the upper and lower levels. Due to the absolute benefit of the royal power, it has obtained the political consolidation. Under the influence of Confucian cultural concepts, Chinese architecture landscape design generally has strict spatial order, and pays attention to the symmetry and balance of the layout. For example, the design concepts of the Forbidden City in Beijing highlights the impact of Confucian ritual and music culture ideas on Chinese architectural landscape, and the strict hierarchical system of the feudal emperors' power. In summary, the rites and music supplement each other. An ideal architectural design, or an ideal landscape design must have the spirit of rites and music.

"Solidarity" in Confucian cultural concepts is the concept of Chinese architectural landscape essential design. From nature, considers the Confucianism as the creative foundation, grasps the natural consciousness and atmosphere in creative elements, makes people enjoy nature's simplicity, serene, rationality and eternalness from the body and mind, and feels the happiness of the life. "Solidarity" in Confucian cultural concepts generally considers the benevolent as the foundation, takes the music as the influence, and pays attention to the personality temperament and the character cultivation. The aesthetic essence of "solidarity" in Confucian cultural concepts is the unity of beauty and goodness, which considers the ethics and morality as the foundation of aesthetic activities, and experiences the moral character in the aesthetic and natural feeling. Confucius' natural aesthetic view is "solidarity", which attaches the moral concepts such as benevolent, righteousness, rites, intellectual and integrity to the natural scenery, and experiences moral values in the natural landscape.

The cultural connotations of plants used in the design of Chinese architectural landscape constitute the traditional unique aesthetic ways and design concepts of Chinese architectural landscape design landscaping art. Confucian culture takes an adaptive and respected attitude towards nature, and advocates that a close and harmonious relationship should be established between people and nature. This Confucian culture, if reflected in the architectural landscape design application, is the natural beauty of admiring nature and pursuing natural fun. Confucian culture concepts provide a completely rational theoretical basis and design ideas for Chinese architectural landscape design, which determines the direction of basic style of Chinese architectural landscape design art.

"Harmony" in Confucian cultural concepts is the concept of Chinese architectural landscape aesthetic design. In the process of the development of Chinese architectural landscape design art, Confucian moderation concept is materialized as the pursuit of "beauty of harmony". China's architectural landscape design art is also the best embodiment of the Confucian culture of the "beauty of harmony" such as the Humble Administrator's Garden and Lingering Garden in Suzhou, Summer Palace in Beijing and Emperor Kangxi's Summer Mountain Resort in Chengde, which are known as China's four famous gardens. The strong sense of beauty of harmony is placed on the Chinese architectural landscape design art so that it has a strong significance of social harmony. Confucian cultural concepts provide a more complete theoretical basis of "beauty of harmony" for Chinese architectural landscape design. In regards to Chinese architectural landscape design artistic aesthetic, the designed architectural landscape image should have a certain principle of overall beauty, the overall and local rhythm, and the harmony and unity of proportion and scale. The understanding of the beauty of harmony and unity in Chinese architectural landscape design art should not only watch its appearance, but also further realize the profound meaning of Confucian "beauty of harmony". Chinese architectural landscape harmonious design concept is the concrete embodiment of the symmetric beauty of "admiring harmony and moderation" in Confucian aesthetic concepts. The "admiring moderation" in Confucianism creates a moral aesthetic principle with rich harmonious sentiment, and has a significant impact on creative ideas, architectural style and overall pattern of Chinese traditional architectural landscape.

\section{Summary}

Confucian culture has a very rich connotation, including the persevering spirit of following the right track, the tolerant character of the great virtue and harmonious ideal of advocating harmony. 
Chinese architectural landscape design art reflects the spiritual characteristics of Confucian culture such as tolerant consciousness, humanistic spirit beyond the utilitarian and personality pursuit of being sages and men of virtue. Confucian culture acts as a carrier of culture, and produces its unique Chinese architectural landscape artistic spirit. It can be seen from the development of Chinese architectural landscape art, the architectural landscape with the performance of Chinese aesthetic characteristics and natural values is not just limited to the visual experience of modeling and color, as well as the psychological description of the conquest of nature by human in general sense. The more important thing should be deep understanding of Chinese Confucian culture. As a practical material product, China's architectural landscape has become an important category of Chinese traditional art with its superb skill and unique style, and has become an important part of Chinese architecture landscape spirit culture with its rich ideological connotation.

\section{References}

[1] QIAN Haiyue. Effect of Confucianism on Chinese traditional architectural form [J] Journal of Jiangsu Architectural Vocational and Technical College, 2016, (04): 28-31.

[2] JIAO Kehua. Confucian cultural concepts in Chinese garden landscape plant design [J]. China Population, Resources and Environment, 2015, (S2): 224-228.

[3] ZHOU Yuan. Effect of Confucianism on Chinese style [J]. Art and Design (Theory), 2010, (04): 115-117.

[4] YANG Nan. On the ritual and musical ideas in Chinese ancient architectural design concepts [J]. Meiyuan, 2009, (06): 82-84.

[5] XIA Yuan. On the influence of Confucianism on Chinese folk architecture [J]. Sichuan Architecture, 2006, (06): 44-46.

[6] WANG Fenghui. On Zen and landscape design [J]. Chinese Garden, 2004, (05): 78-81. 